\title{
ПРОТИВОМИКРОБНАЯ АКТИВНОСТЬ ВЫДЕЛЕННЫХ БИОЛОГИЧЕСКИ АКТИВНЫХ ВЕЩЕСТВ И ЭКСТРАКТА КОРНЯ GLYCYRRHIZA GLABRA L.
}

\author{
() О.В. Астафьева", Л.Т. Сухенко, М.А. Егоров \\ Астраханский государственный университет, пл. Шаумяна, 1, Астрахань, \\ 41400 (Россия), e-mail: astra39@list.ru
}

\begin{abstract}
Изучена противомикробная активность выделенных в виде фракций биологически активных веществ корня Glycyrrhiza glabra L., произрастающей в Астраханском регионе. Методом высокоэффективной жидкостной хроматографии (ВЭЖХ) получен качественный и количественный состав фракций и экстракта корня Glycyrrhiza glabra L. по содержанию глицирризина и $18 \beta$-глицирретовой кислоты.

Ключевые слова: солодка голая, Glycyrrhiza glabra L., глицирризин, 18ß-глицирретовая кислота, противомикробная активность, ВЭЖХ.
\end{abstract}

\section{Введение}

Солодка голая Glycyrrhiza glabra L. (семейство Fabaceae) - широко известное лекарственное растение, произрастающее в разных частях мира (Россия, Турция, Египет, Италия, Испания, Китай, Казахстан, Узбекистан и др.). Солодка голая используется в пищевой, косметической промышленности, в фармакологии и медицине при лечении заболеваний дыхательной системы, язвы желудка, болезни Аддисона, заболеваний печени и др. [1,2]. Глицирризиновая кислота, или глицирризин - один из основных биологически активных компонентов корня Glycyrrhiza glabra. Обнаружена противовирусная активность глицирризина и $18 \beta$-глицирретовой кислоты по отношению к вирусу ВИЧ-1 [3]. Хорошо изучены противомикробные и антиоксидантные свойства компонентов корня солодки голой [1-7].

\section{Экспериментальная часть}

Объектами исследования служили экстракт 50\% спиртового раствора корня Glycyrrhiza glabra, произрастающей в Астраханском регионе и выделенные из него фракции.

Противомикробную активность исследовали на непатогенных тест-микроорганизмах Staphylococcus aureus ВКПМ В-1899, Escherichia coli СК ВКПМ В-1911 и Bacillus subtilis ВКПМ В-1919, полученные из Всероссийской коллекции промышленных микроорганизмов ФГУП ГосНИИ генетики.

Корни Glycyrrhiza glabra подвергали экстрагированию 50\% этиловым спиртом в соотношении $1: 5$. Смесь в емкости из темного стекла оставляли на 7 суток при постоянном перемешивании. Полученные извлечения фильтровали, а затем стерилизовали и выпаривали спирт в суховоздушном стерилизаторе при температуре $85^{\circ} \mathrm{C}$.

Фракции получали в результате колоночной жидкостной хроматографии. Элюирование биологиче-

Астафьева Оксана Витальевна - старший научный сотрудник лаборатории биотехнологий, тел.: (8512) 5249-95, факс: (8512) 52-82-64, e-mail: astra39@list.ru Сухенко Людмила Тимофеевна - доцент кафедры биотехнологии и биоэкологии, кандидат биологических наук, тел.: (8512) 52-49-95, факс: (8512) 52-82-64, e-mail: sukhenko@list.ru

Егоров Михаил Алексеевич - заведующий кафедрой биотехнологии и биоэкологии, заведующий лабораторией биотехнологий, доктор биологических наук, профессор, тел. (8512) 52-49-95, факс: (8512) 52-82-64, e-mail: egorovs.mail@gmail.com ски активных веществ Glycyrrhiza glabra проводили $1 \%$ спиртовым раствором (90\% этанол) аммиака в колонке $(h=25 \mathrm{~cm}, d=2,5 \mathrm{~cm})$; выделили 5 фракций.

Исследования полученных фракций экстракта корня Glycyrrhiza glabra проводили на жидкостном хроматографе Agilent 1200 (Agilent Technologies, Вальдброн, Германия), соединенным с массспектрометром API 4000 (Applied Biosystem/MDS SCIEX, Конкорд, Онтарио, Канада) и снабженном

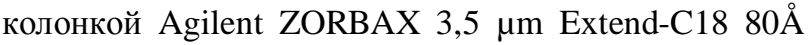

\footnotetext{
* Автор, с которым следует вести переписку.
} 
4,6×150 мм (Agilent Technologies, Вальдброн, Германия). В качестве подвижной фазы использовали смесь метанола и 0,05\% раствора муравьиной кислоты. Детектирование осуществляли при длинах волн: 254 нм, 280 нм, 275 нм, 330 нм и 350 нм. В процессе хроматографирования состав смеси изменялся от 0 до $100 \%$. Скорость потока составляла 0,5 мл/мин, объем вводимой пробы - 10 мкл. На первом этапе были проведены наблюдения за хроматографическим поведение стандартных образцов глицирризиновой кислоты и $18 \beta$ глицирретиновой кислоты (Sigma-Aldrich).

Противомикробную активность определяли методом диффузии в агаровую среду, засеянную микроорганизмами с определением диаметров зон задержки роста (ДЗЗР) микробов вокруг фракций и методом серийных разведений, как описано ранее [8].

\section{Обсуждение результатов}

В таблице 1 представлен качественный и количественный состав исследуемых фракций экстракта корня Glycyrrhiza glabra по содержанию основных компонентов - глицирризиновой кислоты и $18 \beta$-глицирретовой кислоты.

Результаты, представленные в таблице 1, показывают, что наибольшая концентрация глицирризиновой кислоты была обнаружена во фракции Е5, но в целом по содержанию данного вещества между фракциями E3, E4 и E5 нет значительных различий. 18ß-глицирретиновая кислота присутствовала на уровне предела обнаружения в большинстве исследуемых фракций.

Результаты исследования противомикробной активности фракций $50 \%$ спиртового экстракта корня Glycyrrhiza glabra представлены в таблице 2.

Исследовали противомикробное действие фракций экстракта корня солодки голой, полученных в результате препаративной колоночной хроматографии.

Как видно из таблицы 2, противомикробное действие по отношению к культуре $S$. aureus было обнаружено у фракций E4 и Е5, концентрация глицирризина и $18 \beta$-глицирретовой кислоты в которых наибольшая, по сравнению с другими исследуемыми фракциям. Причем фракция Е4 проявила противомикробное действие по отношению ко всем трем тест-культурам (St.aureus, E. coli, B. subtilis). Фракции Е3 и E2 показали одинаковое противомикробное действие по отношению к непатогенным штаммам E. coli и B. subtilis. Но минимальная ингибирующая концентрация (МИК) фракции Е2 выражена более по отношению к E. coli (250 мкг/мл), а у Е3 - по отношению к B. subtilis (500 мкг/л) (табл. 2). Концентрация глицирризиновой кислоты и $18 \beta$-глицирретовой кислоты во фракции Е3 наибольшая (табл. 1). Как видно, в представленных исследованиях, противомикробное действие по отношению к тест-культурам непатогенных штаммов S. aureus, E. coli и B. subtilis проявлялось с увеличением концентрации глицирризиновой и глицирретовой кислот в экстрактах Glycyrrhiza glabra.

Таблица 1. Количественное содержание глицирризиновой кислоты и $18 \beta$-глицирретовой кислоты во фракциях 50\% спиртового экстракта корня Glycyrrhiza glabra

\begin{tabular}{|c|c|c|c|c|}
\hline \multirow[b]{2}{*}{ Фракции } & \multicolumn{2}{|c|}{ Концентрация соединений (мг) в сухом веществе (г) } & \multicolumn{2}{|c|}{ Массовая доля соединений на сухой вес образца, \% } \\
\hline & $\begin{array}{c}\text { глицирризиновая } \\
\text { кислота }\end{array}$ & $\begin{array}{l}\text { 18ß-глицирретовая } \\
\text { кислота (диапазон) }\end{array}$ & $\begin{array}{c}\text { глицирризиновая } \\
\text { кислота }\end{array}$ & $\begin{array}{c}\text { 18ß-глицирретовая ки- } \\
\text { слота }\end{array}$ \\
\hline E1 & 3,4 & $4 \cdot 10^{-4}-1 \cdot 10^{-3 *}$ & 0,34 & - \\
\hline E2 & 2,5 & $1 \cdot 10^{-3}-3 \cdot 10^{-3}$ & 0,25 & - \\
\hline E3 & 4,7 & $9 \cdot 10^{-4}-1 \cdot 10^{-3}$ & 0,47 & - \\
\hline E4 & 4,6 & $5 \cdot 10^{-4}-2 \cdot 10^{-3}$ & 0,46 & - \\
\hline E5 & 5,2 & $1 \cdot 10^{-3}-4 \cdot 10^{-3}$ & 0,52 & - \\
\hline экстракт & 516 & $1 \cdot 10^{-4}-4 \cdot 10^{-4}$ & 51,6 & - \\
\hline
\end{tabular}

"Диапазон определения содержания 18ß-глицирретовой кислоты

Таблица 2. Противомикробное действие экстракта корня Glycyrrhiza glabra и выделенных из него фракций

\begin{tabular}{|c|c|c|c|c|c|c|}
\hline \multirow[t]{2}{*}{ Фракции } & E.coli & St. aureus & B. subtilis & E.coli & St. aureus & B. subtilis \\
\hline & \multicolumn{3}{|c|}{ Д3ЗР', мм } & \multicolumn{3}{|c|}{ МИК $^{2}$, мкг/Мл } \\
\hline E1 & 0 & 0 & 0 & 0 & 0 & 0 \\
\hline E2 & $16,0 \pm 3,4$ & 0 & $6,5 \pm 3,1$ & $62,5 \pm 9,5$ & 0 & $1000,0 \pm 0,0$ \\
\hline E3 & $14,5 \pm 2,3$ & 0 & $6,6 \pm 2,8$ & $125 \pm 19,4$ & 0 & $62,5 \pm 13,9^{*}$ \\
\hline E4 & $15,8 \pm 0,7^{*}$ & $6,7 \pm 1,2$ & $12,1 \pm 1,3$ & $62,5 \pm 11,3$ & $62,5 \pm 8,9$ & $1000,0 \pm 0,0$ \\
\hline E5 & 0 & $8,3 \pm 0,9$ & 0 & 0 & $250 \pm 21,3$ & 0 \\
\hline Экстракт & $14,1 \pm 3,6$ & $11,5 \pm 2,3$ & $10,5 \pm 6,8$ & 0 & 0 & 0 \\
\hline
\end{tabular}

Примечания. ${ }^{1}$ ДЗЗР $(\mathrm{M} \pm \mathrm{m})$ - диаметры зоны задержки роста микроорганизмов, мм; ${ }^{2} \mathrm{MИК}(\mathrm{M} \pm \mathrm{m})$ - минимальные ингибирующие концентрации, мкг/мл; 0 - отсуствие противомикробного действия; " различия с контролем достоверны при р $\leq 0,05$ 


\section{Выводы}

Установлено, что экстракт корня солодки голой, произрастающей в Астраханской области, проявляет противомикробную активность ко всем трем непатогенным штаммам E.coli, S. aureus, B. subtilis. Выделенные фракции, содержащие повышенные концентрации глицирризиновой и $18 \beta$-глицирретовой кислот, обладали выраженным противомикробным действием. Возможно, более сильное противомикробное действие некоторых фракций и самого 50\% спиртового экстракта обусловлено содержанием некоторых других групп химических компонентов, таких как флавоноидов, сопровождающих фракции производных глицирризиновой кислоты Glycyrrhiza glabra.

\section{Список литературы}

1. Nassiri M., Hosseinzadeh H. Review of pharmacological effects of Glycyrrhiza sp. and its bioacative compounds // Phytotherapy Reserch. 2008. N22. Pp. 709-724.

2. Statti G.A., Tundis R., Sacchetti G., Muzzoli M., Bianchi A., Menichini F. Variability in the content of active constituents and biological activity of Glycyrrhiza glabra // Fitoterapia. 2004. Vol. 75. Pp. 371-374.

3. Плясунова О.А., Егорычева И.П., Федюк Н.В., Покровский А.Г., Балтина Л.А, Муринов Ю.И., Толстиков Г.А. Изучение анти-ВИЧ-активности $\beta$-глицирризиновой кислот // Вопросы вирусологии. 1992. №5. С. $235-237$.

4. Fukai T., Marumo A., Kaitou K., Kanda T., Terada S., Nomura T. Antimicrobial activity of licorice flavonoids against methicillin-resistant Staphylococcus aureus // Fitoterapia. 2002. N73. Pp. 536-539.

5. Gupta V.K., Fatima A., Faridi A., Negi A.S., Shanker K., Kumar J.K., Rahuja N., Luqman S., Sisodia B.S., Saikia D., Darokar M.P., Khanuja P.S. Antimicrobial potential of Glycyrrhiza glabra roots // Journal of ethnopharmacology. 2008. N116. Pp. 377-380.

6. Sukhenko L. The aktivity increase of the peritoneal macrophages of the mise, infected with M. tuberculosis H37Rv, treated with the preparation «GLYCYRFIT» from Glycyrrhiza glabra. Praha, Publishing House «Education and Science». 2011. Pp. 53-56.

7. Sukhenko L.T., Egorov M.A. Activity increase of peritoneal macrophages in mice infected with M. tuberculosis H37Rv, treated with preparation from Glycyrrhiza glabra root $/ / 4^{\text {th }}$ Congress of European Microbiologists FEMS. Geneva, 2011. $251 \mathrm{p}$.

8. Tyrkov A.G., Sukhenko L.T. Synthesis and antimicrobial activity $\omega$-substituted nitro-1,2,4-oxadiazione-5carbaldehydrazones // Pharmaceutical Chemistry Journal. 2004. Vol. 38, N7. Pp. 376-378.

Поступило в редакиию 22 ноября 2012 г.

Astafyeva O.V. , Sukhenko L.T., Egorov M.A. ANTIBACTERIAL ACTIVITY OF EXTRACTED BIOLOGICALLY ACTIVE SUBSTANCES AND EXTRACTS OF ROOTS OF GLYCYRRHIZA GLABRA L.

Astrakhan state University, pl.Shaumiana 1, 414000 (Russia), e-mail: astra39@list.ru

We studied antibacterial activity of extracted biologically active substances in the form of fractions Glycyrrhiza glabra L., cultivated/grown in the Astrakhan region. We used the method of high performance liquid chromatography (HPLC) and obtained qualitative and quantitative compound of glycyrrhizin and $18 \beta$ - glycyrrhetinic acid in fractions and extracts of root of Glycyrrhiza glabra L.

Keywords: licorice, Glycyrrhiza glabra L., glycyrrhizin, 18ß-glycyrrhetinic acid, antibacterial activity, HPLC.

\section{References}

1. Nassiri M., Hosseinzadeh H. Phytotherapy Reserch, 2008, no. 22, pp. 709-724.

2. Statti G.A., Tundis R., Sacchetti G., Muzzoli M., Bianchi A., Menichini F. Fitoterapia, 2004, vol. 75, pp. 371-374.

3. Pliasunova O.A., Egorycheva I.P., Fediuk N.V., Pokrovskii A.G., Baltina L.A, Murinov Iu.I., Tolstikov G.A. Voprosy virusologii, 1992, no. 5, pp. 235-237. (in Russ.).

4. Fukai T., Marumo A., Kaitou K., Kanda T., Terada S., Nomura T. Fitoterapia, 2002, no. 73, pp. 536-539.

5. Gupta V.K., Fatima A., Faridi A., Negi A.S., Shanker K., Kumar J.K., Rahuja N., Luqman S., Sisodia B.S., Saikia D., Darokar M.P., Khanuja P.S. Journal of ethnopharmacology, 2008, no. 116, pp. 377-380.

6. Sukhenko L. The aktivity increase of the peritoneal macrophages of the mise, infected with M. tuberculosis H37Rv, treated with the preparation «GLYCYRFIT» from Glycyrrhiza glabra. Praha, Publishing House «Education and Science». 2011. Pp. 53-56.

7. Sukhenko L.T., Egorov M.A. $4^{\text {th }}$ Congress of European Microbiologists FEMS. Geneva, 2011. 251 p.

8. Tyrkov A.G., Sukhenko L.T. Pharmaceutical Chemistry Journal, 2004, vol. 38, no. 7, pp. 376-378.

\footnotetext{
* Corresponding author.
} 
